American J. of Engineering and Applied Sciences 2 (4): 584-589, 2009

ISSN 1941-7020

(C) 2009 Science Publications

\title{
Numerical Investigation of an Industrial Robot Arm Control Problem Using Haar Wavelet Series
}

\author{
${ }^{1}$ S. Nandhakumar, ${ }^{2}$ V. Selladurai and ${ }^{3}$ S. Sekar \\ ${ }^{1}$ Department of Mechanical Engineering, \\ Angel College of Engineering and Technology, Tirupur, India \\ ${ }^{2}$ Department of Mechanical Engineering, \\ Coimbatore Institute of Technology, Coimbatore, India \\ ${ }^{3}$ Department of Mathematics, Anbanathapuram Vahaira Charities College, Myladuthurai, India
}

\begin{abstract}
Problem statement: An error minimization in robot arm dynamics improves operations and performance of production systems. Many contributions have been made in area of robot dynamics since the earliest study more than two decades, but, a number of researchers are still contributing various principles and new techniques for the best use of robots in reality, especially in the field of industry, as this field of study is inexhaustible. This study attempted to analyze the performance of an industrial robot by comparing solutions obtained using RK method and Single-Term Haar Wavelet Series (STHWS) method. Exact solution of system of equations representing arm model of a robot had been compared with corresponding discrete solution at different time intervals. Absolute error between exact and discrete solutions had also been determined to suggest the method of improving performance of a robot. Approach: Haar wavelet had been applied extensively for signal processing in communications and proved to be a useful mathematical tool for dynamical systems. In this study, STWHS method had been used for solving differential equations. Result had been obtained and compared with exact solutions. Results: Error had been compared by exact solutions, RK and STHWS solutions were reported for non-singular systems and estimated as almost zero. The validation had been carried out with reference to earlier research output appeared in this field of study. Conclusion/Recommendations: For robot arm model selected for study, solution obtained by STHWS was found to be accurate from results.
\end{abstract}

Key words: Robot dynamics, Runge-Kutta methods, single-term Haar wavelet series, non-singular systems

\section{INTRODUCTION}

In an automated production system, the presence of robots operations and its performance improves the quality of the manufacturing systems. It is essential to study the performance of a robot by widely used techniques in mathematical modeling. Literatures are available on the analysis of performances of robots using differential equations. These equations provide simple analytical solutions without non- linear differential equations leading to limited constraints. The robotic system performance can be affected due to the interaction between the joint motion and the angular motion of the constrained surface in addition to the effects of differential angular velocity and the joint torque ${ }^{[1]}$. The uncertainty in constraint functions affects the dynamic modeling and simulation of a manipulator $^{[2,3]}$. The performance of a robot arm with respect to control accuracy and mechanical efficiency is based on the effects of manipulator gravity ${ }^{[8]}$. The various techniques have been suggested to reduce the inaccuracy level and the error ${ }^{[4-8]}$.

Mathematical models of robot dynamics to predict coupling effects and dynamic nonlinearities, often are used to achieve maximum accuracy and performance in robot control. The design of a robot control system is made complicated by the non-linear and coupled characteristics of its dynamics. The dynamics of a robot can be described by a set of coupled non-linear equations in the form of gravitational torques, coriolis and centrifugal forces. The significance of these forces depends on the physical parameters of the robot, the

Corresponding Author: S. Nandhakumar, Department of Mechanical Engineering,

Angel College of Engineering and Technology, Tirupur, Coimbatore-641 006, India

Tel: 919942308180 
load it carries and the speed at which the robot operates. To reach the level of accuracy, compensation for the above mentioned parameter variations and disturbances, become much more critical. Hence the design of the control system becomes much more complex.

The numerical techniques are well proven method for solving the system of differential equations, produces the stable, efficiency and accuracy ${ }^{[9,10]}$. Recently, Haar wavelet have been applied to signal processing in communication research and physics research and proving to be wonderful mathematical tool. The main advantage in this method is to convert a differential equations into algebraic equations; hence, solution identification and optimization procedures are either reduced or simplified ${ }^{[10,11]}$.

An attempt has been made in this study to analyze an industrial robot and its control problem while minimizing the error of solutions to position the robot accurately by using STWHS for non-singular system robot arm model. The obtained solution have been compared with stated solutions ${ }^{[12,13]}$ and is tabulated.

Robot arm model: The dynamics of a robot arm can be represented by ${ }^{[1,5,13]}$ :

$$
\mathrm{T}=\mathrm{A}(\mathrm{Q}) \ddot{\mathrm{Q}}+\mathrm{B}(\mathrm{Q}, \dot{\mathrm{Q}})+\mathrm{C}(\mathrm{Q})
$$

Where:

$$
\begin{array}{ll}
\mathrm{A}(\mathrm{Q}) & =\text { Coupled inertia matrix } \\
\mathrm{B}(\mathrm{Q}, \dot{\mathrm{Q}}) & =\text { The matrix of coriolis and centrifugal forces } \\
\mathrm{C}(\mathrm{Q}) & =\text { The Gravity matrix } \\
\mathrm{T} & =\text { The Input torques applied at various joints }
\end{array}
$$

For a robot with two degrees of freedom, under the assumption of lumped equivalent masses and mass lesslinks, the dynamics are represented in terms of systems of non-linear equations and by applying the method of reduction, it has been represented in terms of the following system of linear equation of time invariant case. The behavior of the robot arm model has been completely described by state equations and the state equations provides perfect controls ${ }^{[14,15]}$ :

$$
\begin{aligned}
& \dot{\mathrm{e}}_{1}=\mathrm{x}_{2} \\
& \dot{\mathrm{x}}_{2}=\mathrm{B}_{10} \mathrm{~T}_{1}-\mathrm{A}_{11} \mathrm{X}_{2}-\mathrm{A}_{10} \mathrm{e}_{1} \\
& \dot{\mathrm{e}}_{3}=\mathrm{x}_{4} \\
& \dot{\mathrm{x}}_{4}=\mathrm{B}_{20}^{2} \mathrm{~T}_{2}-\mathrm{A}_{21}^{2} \mathrm{X}_{4}-\mathrm{A}_{20}^{2} \mathrm{e}_{3}
\end{aligned}
$$

As of the form $\operatorname{Ki}(t)=A x(t)+B u(t)$. The values of the parameters concerning the joints- 1 are:

$$
\begin{aligned}
& \mathrm{A}_{10}=0.1730 \\
& \mathrm{~A}_{11}=-0.2140 \\
& \mathrm{~B}_{10}=0.00265
\end{aligned}
$$

The values of parameters concerning the joint -2 are:

$$
\begin{aligned}
& \mathrm{A}_{20}=0.0438 \\
& \mathrm{~A}_{21}=0.3610 \\
& \mathrm{~B}_{20}=0.0967
\end{aligned}
$$

And by choosing $T_{1}=1$ and $T_{2}=1$ with initial condition:

$$
\left[\begin{array}{l}
\mathrm{e}_{1}(0) \\
\mathrm{x}_{2}(0) \\
\mathrm{e}_{3}(0) \\
\mathrm{x}_{4}(0)
\end{array}\right]=\left[\begin{array}{c}
-1 \\
0 \\
-1 \\
0
\end{array}\right]
$$

The corresponding exact solution is:

$$
\begin{aligned}
\mathrm{e}_{1}(\mathrm{t})= & \mathrm{e}^{0.107 \mathrm{t}}[-1.15317919 \cos (0.401934074 \mathrm{t}) \\
& +0.306991074 \sin (0.401934074 \mathrm{t})]+0.15317919
\end{aligned}
$$

$$
\begin{aligned}
\mathrm{x}_{2}(\mathrm{t})= & \mathrm{e}^{0.107 \mathrm{t}}[0.463502009 \sin (0.401934074 \mathrm{t}) \\
& +0.123390173 \cos (0.401934074 \mathrm{t})] \\
& +0.107 \mathrm{e}^{0.107 \mathrm{t}}[-1.15317919 \cos (0.401934074 \mathrm{t}) \\
& +0.306991074 \sin (0.401934074 \mathrm{t})]
\end{aligned}
$$

$$
\begin{aligned}
\mathrm{e}_{3}(\mathrm{t})= & 1.029908976 \mathrm{e}^{-0.113404416 \mathrm{t}} \\
& -6.904124484 \mathrm{e}^{-0.016916839 \mathrm{t}} \\
\mathrm{x}_{4}(\mathrm{t})= & -0.116795962 \mathrm{e}^{-0.11340416 \mathrm{t}} \\
& +0.116795962 \mathrm{e}^{-0.016916389 \mathrm{t}}
\end{aligned}
$$

Single term Haar wavelet series: The orthogonal set of Haar wavelets $h_{n}(t)$ is a group of square waves with magnitude of \pm 1 in some intervals and zeros elsewhere ${ }^{[9-11]}$. In general:

$$
\left.\begin{array}{l}
h_{n}(t)=h_{1}\left(2^{j} t-k\right), n=2^{j}+k, \\
j \geq 0,0 \leq k<2^{j}, n, j, k \in Z
\end{array}\right\}
$$




$$
\mathrm{h}_{1}(\mathrm{t})=\left\{\begin{array}{l}
1,0 \leq \mathrm{t}<\frac{1}{2} \\
-1, \frac{1}{2} \leq \mathrm{t}<1
\end{array}\right.
$$

Namely, each Haar wavelet contains one and just one square wave and is zero elsewhere. Just these zeros make Haar wavelets to be local and very useful in solving singular and nonsingular systems.

Function approximation: Any function $\mathrm{y}(\mathrm{x}) \in \mathrm{L}^{2}[0,1]$ can be decomposed as:

$$
\left.\begin{array}{l}
y(t)=\sum_{i=0}^{\infty} c_{n} h_{n}(t), n=2^{j}+k, \\
j \geq 0,0 \leq k<2^{j}, t \in[0,1]
\end{array}\right\}
$$

Where:

$$
c_{n}=2^{j} \int_{0}^{1} y(t) h_{n}(t) d t
$$

The series expansion of $\mathrm{y}(\mathrm{t})$ contains infinite terms. If $y(t)$ is piecewise constant by itself, or may be approximated as piecewise constant during each subinterval, then $\mathrm{y}(\mathrm{t})$ will be terminated at finite terms, that is:

$$
\begin{aligned}
& \mathrm{y}(\mathrm{t}) \approx \sum_{\mathrm{n}=0}^{\mathrm{m}-1} \mathrm{c}_{\mathrm{n}} \mathrm{h}_{\mathrm{n}}(\mathrm{t})=\mathrm{c}_{(\mathrm{m})}^{\mathrm{T}} \mathrm{h}_{(\mathrm{m})}(\mathrm{t}), \mathrm{t} \in[0,1] \\
& \mathrm{c}_{(\mathrm{m})}^{\mathrm{T}} \cong\left[\mathrm{c}_{0} \mathrm{c}_{1} \ldots \mathrm{c}_{\mathrm{m}-1}\right] \\
& \mathrm{h}_{(\mathrm{m})}(\mathrm{t}) \cong\left[\mathrm{h}_{0}(\mathrm{t}) \mathrm{h}_{1}(\mathrm{t}) \ldots \mathrm{h}_{\mathrm{m}-1}(\mathrm{t})\right]^{\mathrm{T}}
\end{aligned}
$$

where, " $T$ " means transpose and $m=2^{j}$.

The product operational matrix of the Haar wavelet: The first four Haar function vectors which $\mathrm{x}=\mathrm{n} / 8, \mathrm{n}=1,3,5,7$ can be expressed the following:

$$
\begin{aligned}
& \mathrm{h}_{(1 / 8)}=[1,1,1,0]^{\mathrm{T}}, \mathrm{h}_{(3 / 8)}=[1,1,-1,0]^{\mathrm{T}} \\
& \mathrm{h}_{(5 / 8)}=[1,-1,0,1]^{\mathrm{T}} \mathrm{h}_{(7 / 8)}=[1,-1,0,-1]^{\mathrm{T}}
\end{aligned}
$$

This can be written in matrix form as:

$$
\mathrm{H}_{(4)}=\left[\begin{array}{l}
\mathrm{h}_{(4)}(1 / 8), \mathrm{h}_{(4)}(3 / 8), \mathrm{h}_{(4)}(3 / 8), \\
\mathrm{h}_{(4)}(5 / 8), \mathrm{h}_{(4)}(7 / 8)
\end{array}\right]^{\mathrm{T}}
$$

$$
=\left[\begin{array}{cccc}
1 & 1 & 1 & 1 \\
1 & 1 & -1 & -1 \\
1 & -1 & 0 & 0 \\
0 & 0 & 1 & -1
\end{array}\right]
$$

In general, we have:

$\mathrm{H}_{(\mathrm{m})}=\left[\begin{array}{l}\mathrm{h}_{(\mathrm{m})}(1 / 2 \mathrm{~m}), \mathrm{h}_{(\mathrm{m})}(3 / 2 \mathrm{~m}), \mathrm{h}_{(\mathrm{m})}(3 / 2 \mathrm{~m}), \\ \cdots . \mathrm{h}_{(\mathrm{m})}((2 \mathrm{~m}-1) / 2 \mathrm{~m}) .\end{array}\right]$

$\mathrm{H}_{(1)}=[1], \mathrm{H}_{(2)}=\left[\begin{array}{cc}1 & 1 \\ 1 & -1\end{array}\right]$

The integration of the vector $h_{(m)}(t)$ is given by:

$\int \mathrm{h}_{(\mathrm{m})}(\mathrm{t}) \mathrm{dt}=\mathrm{P}_{(\mathrm{m})} \mathrm{h}_{(\mathrm{m})}(\mathrm{t}), \mathrm{t} \in[0,1]$

where, $P_{(m)}$ is the $m \times m$ operational matrix and is given by:

$\mathrm{P}_{(\mathrm{m})}=1 / 2\left[\begin{array}{cc}2 \mathrm{mP}_{(\mathrm{m} / 2)} & -\mathrm{H}_{(\mathrm{m} / 2)} \\ \mathrm{H}_{(\mathrm{m} / 2)}^{-1} & 0\end{array}\right]$

where, $P_{(1 \times 1)}=[1 / 2]$, so:

$$
\begin{aligned}
& P_{(2)}=1 / 4\left[\begin{array}{cc}
2 & -1 \\
1 & 0
\end{array}\right], P_{(4)}=1 / 16\left[\begin{array}{cccc}
8 & -4 & -2 & -2 \\
4 & 0 & -2 & 2 \\
1 & 1 & 0 & 0 \\
1 & -1 & 0 & 0
\end{array}\right] \\
& P_{(8)}=1 / 64\left[\begin{array}{cccccccc}
32 & -16 & -8 & -8 & -4 & -4 & -4 & -4 \\
16 & 0 & -8 & 8 & -4 & -4 & 4 & 4 \\
4 & 4 & 0 & 0 & -4 & 4 & 0 & 0 \\
-1 & 4 & 0 & 0 & -4 & 4 & 0 & 0 \\
1 & 1 & 2 & 0 & 0 & 0 & 0 & 0 \\
1 & 1 & -2 & 0 & 0 & 0 & 0 & 0 \\
1 & -1 & 0 & 2 & 0 & 0 & 0 & 0 \\
1 & -1 & 0 & -2 & 0 & 0 & 0 & 0
\end{array}\right]
\end{aligned}
$$

Solution for linear systems: Consider a linear system of the following form:

$$
\mathrm{K} \dot{\mathrm{x}}(\mathrm{t})=\mathrm{Ax}(\mathrm{t})+\mathrm{Bu}(\mathrm{t}), \mathrm{x}(0)=\mathrm{x}_{0}
$$

where, $\mathrm{t} \in[0,1 / \mathrm{m}]$. 
In the normalized interval with $\tau=$ m.t

$\mathrm{K} \dot{\mathrm{x}}(\tau)=\frac{1}{\mathrm{~m}}[\mathrm{Ax}(\tau)+\mathrm{Bu}(\tau)], \mathrm{x}(0)=\mathrm{x}_{0}$

where, $\tau \in[0,1]$.

Now expressing $\dot{\mathrm{x}}(\tau), \mathrm{x}(\tau)$ and $\mathrm{u}(\tau)$ in singleterm Haar series as:

$\dot{\mathrm{x}}_{\mathrm{i}}(\tau)=\mathrm{a}_{\mathrm{i}} \mathrm{h}_{0}(\tau)$

$\mathrm{x}_{\mathrm{i}}(\tau)=\mathrm{b}_{\mathrm{i}} \mathrm{h}_{0}(\tau)$ and $\mathrm{u}_{\mathrm{i}}(\tau)=\mathrm{r}_{\mathrm{i}} \mathrm{h}_{0}(\tau)$

And the following recursive relationship is obtained with $\mathrm{P}=\frac{1}{2}$ :

$b_{i}=\frac{1}{2} a_{i}+x_{i}(j-1)$

$x_{i}(j)=a_{i}+x_{i}(j-1)=2 b_{i}-x_{i}(j-1)$

where, $i, j=0,1, \ldots, n \in N$. Substituting Eq. 12 and 13 into Eq. 11, we obtain nonlinear algebraic equations and they may be solved to obtain $\mathrm{x}_{\mathrm{i}}$. The single-term Haar wavelets method with piecewise constant orthogonal functions is an extension of the single-term algorithm Eq. 10, that avoids the inverse of the big matrix induced by the Kronecker product. This approach is applicable for any transform with piecewise constant basis. Therefore, in this study, the above algorithm is used in solving the robot arm control problems to avail the advantages of its fast, local and multiplicative properties.

\section{RESULTS}

The following Table 1-4 show the result obtained for five time intervals. The exact solutions, RK solutions and STHWS solutions are reported with its errors for non-singular systems and graph has been obtained. For calculation $\mathrm{m}$ is taken as 32 . If $\mathrm{m}$ increases the accuracy in values also increases.

\section{DISCUSSION}

In this study, the obtained discrete solutions for the Robot Arm model problem using the STHWS give more accurate values when compared to the classical RK methods. From the Table 1-4 and Fig. 1-4 the following observations are made:
- For the robot arm model selected for study, the solution obtained by STHWS is found to be accurate from the STHWS error

- The error in solutions obtained by both RK and STHWS increases with the increase in time

- The STHWS method yields accurate solution even when it is compared with RK-eight stage seven order solution ${ }^{[12]}$ for non-linear system

$\underline{\text { Table 1: Solutions of the robot arm non singular system model for } \mathrm{e}_{1}(\mathrm{t})}$

\begin{tabular}{|c|c|c|c|c|c|c|}
\hline \multirow[b]{2}{*}{$\begin{array}{l}\text { Solution } \\
\text { No. }\end{array}$} & \multirow[b]{2}{*}{ Time } & \multicolumn{5}{|c|}{$e_{1}(t)$} \\
\hline & & $\begin{array}{l}\text { Exact } \\
\text { solution }\end{array}$ & $\begin{array}{l}\text { RK } \\
\text { solution }\end{array}$ & $\begin{array}{l}\text { RK } \\
\text { error }\end{array}$ & $\begin{array}{l}\text { STHWS } \\
\text { solution }\end{array}$ & $\begin{array}{l}\text { STHWS } \\
\text { error }\end{array}$ \\
\hline 1 & 0.0 & -1.000000 & -1.000000 & 0.0 & -1.000000 & 0.0 \\
\hline 2 & 0.5 & -0.974242 & -0.974239 & $3 \mathrm{E}-06$ & -0.974240 & 2E-06 \\
\hline 3 & 1.0 & -0.894296 & -0.894290 & $6 \mathrm{E}-06$ & -0.894292 & 4E-06 \\
\hline 4 & 1.5 & -0.757677 & -0.757669 & $8 \mathrm{E}-06$ & -0.757671 & $6 \mathrm{E}-06$ \\
\hline 5 & 2.0 & -0.564199 & -0.564189 & $1 \mathrm{E}-05$ & -0.564191 & $8 \mathrm{E}-06$ \\
\hline
\end{tabular}

Table 2: Solutions of the robot arm non singular system model for

\begin{tabular}{|c|c|c|c|c|c|c|}
\hline \multirow[b]{2}{*}{$\begin{array}{l}\text { Solution } \\
\text { No. }\end{array}$} & \multirow[b]{2}{*}{ Time } & \multicolumn{5}{|c|}{$\mathrm{x}_{2}(\mathrm{t})$} \\
\hline & & $\begin{array}{l}\text { Exact } \\
\text { solution }\end{array}$ & $\begin{array}{l}\text { RK } \\
\text { solution }\end{array}$ & $\begin{array}{l}\mathrm{RK} \\
\text { error }\end{array}$ & $\begin{array}{l}\text { STHWS } \\
\text { solution }\end{array}$ & $\begin{array}{l}\text { STHWS } \\
\text { error }\end{array}$ \\
\hline 1 & 0.0 & 0.000000 & 0.000000 & 0.0 & 0.000000 & 0.0 \\
\hline 2 & 0.5 & 0.104525 & 0.104525 & 0.0 & 0.104524 & 1E-06 \\
\hline 3 & 1.0 & 0.216100 & 0.216099 & 1E-06 & 0.216098 & $2 \mathrm{E}-06$ \\
\hline 4 & 1.5 & 0.330447 & 0.330443 & $4 \mathrm{E}-06$ & 0.330444 & 3E-06 \\
\hline 5 & 2.0 & 0.442677 & 0.442671 & $6 \mathrm{E}-06$ & 0.442673 & $4 \mathrm{E}-06$ \\
\hline
\end{tabular}

Table 3: Solutions of the robot arm non singular system model for $\mathrm{e}_{3(\mathrm{t})}$

\begin{tabular}{|c|c|c|c|c|c|c|}
\hline \multirow[b]{2}{*}{$\begin{array}{l}\text { Solution } \\
\text { No. }\end{array}$} & \multirow[b]{2}{*}{ Time } & \multicolumn{5}{|c|}{$\mathrm{e}_{3}(\mathrm{t})$} \\
\hline & & $\begin{array}{l}\text { Exact } \\
\text { solution }\end{array}$ & $\begin{array}{l}\text { RK } \\
\text { solution }\end{array}$ & $\begin{array}{l}\text { RK } \\
\text { error }\end{array}$ & $\begin{array}{l}\text { STHWS } \\
\text { solution }\end{array}$ & $\begin{array}{l}\text { STHWS } \\
\text { error }\end{array}$ \\
\hline 1 & 0.0 & -1.000000 & -1.000000 & 0.0 & -1.000000 & 0.0 \\
\hline 2 & 0.5 & -0.998621 & -0.998618 & $3 \mathrm{E}-06$ & -0.998620 & $1 \mathrm{E}-06$ \\
\hline 3 & 1.0 & -0.994603 & -0.994598 & $5 \mathrm{E}-06$ & -0.994601 & 2E-06 \\
\hline 4 & 1.5 & -0.988113 & -0.988108 & $5 \mathrm{E}-06$ & -0.988110 & $3 \mathrm{E}-06$ \\
\hline 5 & 2.0 & -0.979311 & -0.979305 & $6 \mathrm{E}-06$ & -0.979307 & 4E-06 \\
\hline
\end{tabular}

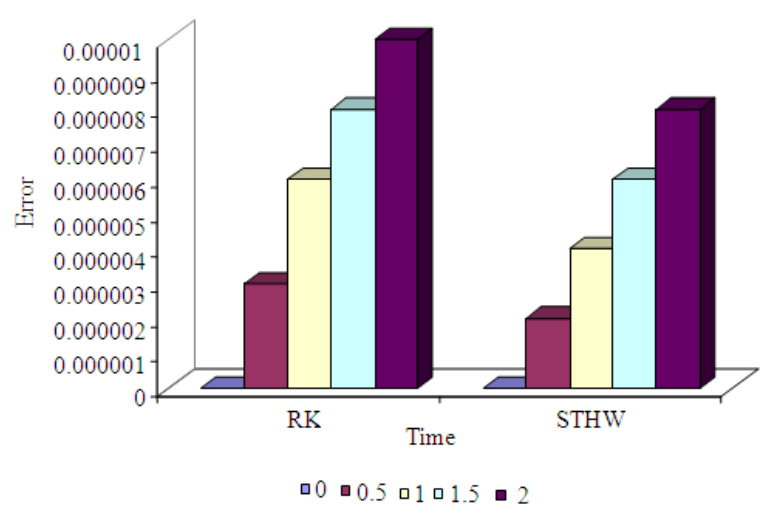

Fig. 1: Error graph non singular system model for $\mathrm{e}_{1}(\mathrm{t})$ 
Table 4: Solutions of the robot arm non singular system model for

\begin{tabular}{lllllll}
\multicolumn{2}{c}{$\mathrm{x}_{4}(\mathrm{t})$} & & \multicolumn{4}{c}{$\mathrm{x}_{4}(\mathrm{t})$} \\
\hline & & & & & \\
Solution & & Exact & RK & RK & STHWS & STHWS \\
No. & Time & solution & solution & error & solution & error \\
\hline 1 & 0.0 & 0.000000 & 0.000000 & 0.0 & 0.000000 & 0.0 \\
2 & 0.5 & 0.005455 & 0.005452 & $3 \mathrm{E}-06$ & 0.005454 & $1 \mathrm{E}-06$ \\
3 & 1.0 & 0.010563 & 0.010559 & $4 \mathrm{E}-06$ & 0.010561 & $2 \mathrm{E}-06$ \\
4 & 1.5 & 0.015343 & 0.015336 & $7 \mathrm{E}-06$ & 0.015340 & $3 \mathrm{E}-06$ \\
5 & 2.0 & 0.019816 & 0.019807 & $9 \mathrm{E}-06$ & 0.019812 & $4 \mathrm{E}-06$ \\
\hline
\end{tabular}

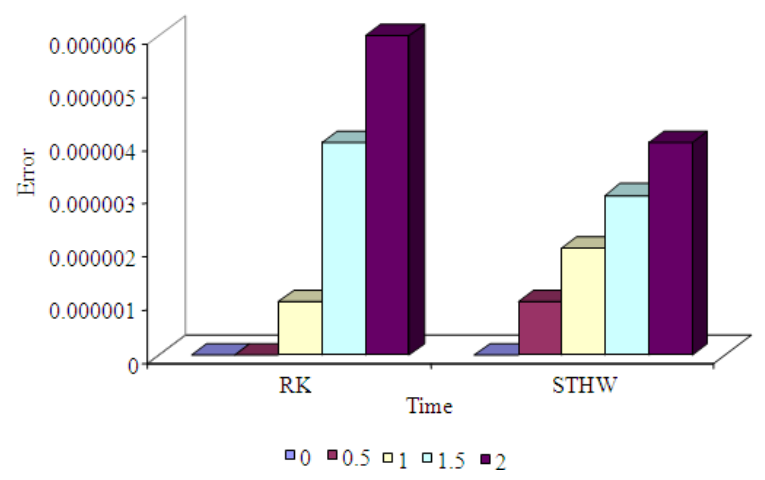

Fig. 2: Error graph non singular system model for $\mathrm{x}_{2}(\mathrm{t})$

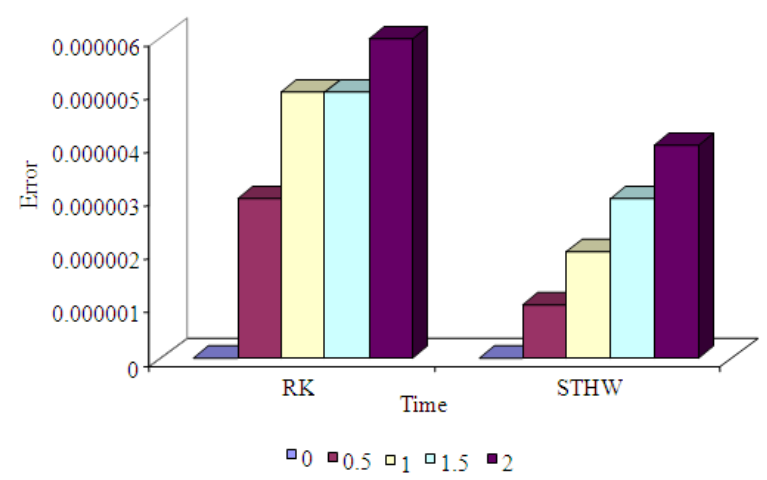

Fig. 3: Error graph non singular system model for $\mathrm{e}_{3}(\mathrm{t})$

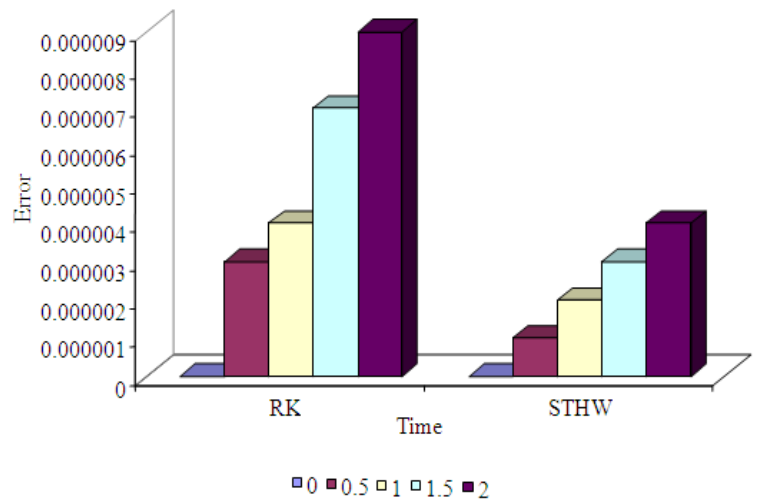

Fig. 4: Error graph non singular system model for $\mathrm{x}_{4}(\mathrm{t})$

\section{CONCLUSION}

Accuracy in the solution for a robot arm model decides the control of the movement of robot. In turn, operational performances of an automated manufacturing system for the future could be improved. In this study, the attempts are made to find the quality of the solution obtained by STHWS compared to that of RK solution for the same condition. From the tables and graph, we observe that the STHWS yields very less error (almost no error). And this STHWS is more suitable for studying the Robot Arm model problem. Moreover, this STHWS method is highly stable because it is based on the Haar wavelet series method, which is also highly stable and hence one can get the solution for any length of time.

\section{REFERENCES}

1. Ata, A.A. and H. Johar, 2004. Dynamic force/motion simulation of a rigid-flexible manipulator during task constrained. Proceedings of the IEEE International Conference on Mechatronics, June 3-5, IEEE Xplore Press, USA., pp: 268-273. DOI: 10.1109/ICMECH.2004.1364450

2. Auzinsh, J. and P. Sliede, 1995. Methods and Software Engineering Tools for Simulation of Robot Dynamics. Automation and Robotics in Construction. Warsaw, Poland, ISBN: 83-8604002-05, pp: 321-328.

3. Chitta, S., P. Cheng, E. Frazzoli and V. Kumar, 2005. RoboTrikke: A novel undulatory locomotion System. Proceedings IEEE International Conference on Robotics and Automation, Apr. 1822, IEEE Xplore Press, USA., pp: 1597-1602. http://ieeexplore.ieee.org/xpl/freeabs_all.jsp?arnum ber $=1570342$

4. Ellis, R.E. and S.L. Ricker, 1994. Two numerical issues in simulating constrained robot dynamics. IEEE. Trans. Syst. Man Cybernet., 24: 19-24. DOI: 10.1109/21.259682

5. Featherstone, R. and D. Orin, 2000. Robot dynamics: Equations and algorithms. Proceeding of IEEE International Conference on Robotics and Automation, Apr. 24-28, IEEE Xplore Press, San Francisco, CA., pp: 826-834. DOI: 10.1109/ROBOT.2000.844153

6. Ho, Y.K., Wang and Y.C. Soh, 2000. Modeling of constrained robot system with constraint uncertainties. J. Robot. Syst., 17: 53-61. http://www3.ntu.edu.sg/home/edwwang/jnlpapers/ hykjrs98.pdf 
7. Hopler, R., M. Stelzer and O.V. Stryk, 2004. Object-oriented dynamics modeling for legged robot trajectory optimization and control. Proceeding of the IEEE Conference on Mechatronics and Robotics (Mechrob), Sept. 1315, Aachen, Germany, pp: 927-977. http://www.sim-opt.de/publ/download/2004-IEEEMechRob.pdf

8. Yamawaki, T. and M. Yashima, 2007. Effect of gravity on manipulation performance of a robotic arm. IEEE International Conference on Robotics and Automation, Apr. 10-14, IEEE Xplore Press, Rome, pp: 4407-4413. DOI: 10.1109/ROBOT.2007.364158

9. Hsiao, C.H., 2005. Numerical solution of stiff differential equations via Haar wavelets. Int. J. Comput. Math., 82: 1117-1123. DOI: 10.1080/00207160512331323308

10. Shi, Z., L.Y. Deng and Q.J. Chen, 2007. Numerical solution of differential equations by using Haar wavelets. Proceeding of the International Conference on Wavelet Analysis and Pattern Recognition, Nov. 2-4, IEEE Xplore Press, Beijing, pp: 1039-1044 DOI: 10.1109/ICWAPR.2007.4421585
11. Bujurke, N.M., C.S. Salimath and Shiralashetti, 2008. Numerical solution of stiff systems from nonlinear dynamics using single-term Haar wavelet series. Int. J. Nonlinear Dyn., 51: 595-605. DOI: 10.1007/s11071-007-9248-8

12. Senthilkumar, S., 2008. An efficient numerical solution for system of second order robot arm problem. Int. J. Eng. Syst. Model. Simulat., 1: 69-78. DOI: 10.1504/IJESMS.2008.018851

13. Murugesan, K., S. Sekar, V. Murugesh and J.Y. Park, 2004. Numerical solution of an Industrial robot arm control problem using the RK-Butcher algorithm. Int. J. Comput. Appli. Technol., 19: 132-138. DOI: 10.1504/IJCAT.2004.003639

14. Paraskevopoulos, P.N. and F.N. Koumboulis, 1991. Decoupling and pole assignment in statespace systems. IEE Proc. Control Theor. Appli., 138: 547-560.

http://ieeexplore.ieee.org/xpl/freeabs_all.jsp?arnum ber $=101348$

15. Paraskevopoulos, P.N., F.N. Koumboulis and C.J. Zervas,1995. Perfect output control for nonsquare generalized state-space systems. IEE Proc. Control Theor. Appli., 142: 119-122. http://cat.inist.fr/?aModele $=$ afficheN\&cpsidt $=3658$ 051 